\title{
EDUCAÇÃO ONLINE E AVAS NA FORMAÇÃO DOCENTE NO ENSINO SUPERIOR
}

Thiago Soares Valentim Grass

Pedagogo e Prof. Especialista Parceiro da Universidade São Judas

Andrea Barbosa Gomes Pereira

Graduada em Letras e Pedagogia, especialista em Gestão Pública Municipal e em Psicopedagogia Clínica e Institucional

Prof. Dr. Gabriel C. D. Lopes, PhD

Professor e Orientador Doutor em Educação / PhD em Psicanálise Clínica Presidente da LUI - Logos University Int.

\section{RESUMO}

Este trabalho tem o objetivo de averiguar o papel dos ambientes virtuais de aprendizagem nos cursos de formação do Ensino Superior. Procura também definir a relação entre esses ambientes virtuais de aprendizagem com as tecnologias digitais de informação e comunicação. A evolução tecnológica e informacional são uma realidade consolidada e discutir aspectos de sua influência no campo da educação é urgente e indispensável. Para isso, empregou-se pesquisa bibliográfica de fontes relevantes sobre o tema. Após essa reflexão, notou-se a importância dos ambientes virtuais de aprendizagem para o sucesso da educação online, principalmente no Ensino Superior.

Palavras-Chave: TDIC, Educação Online, AVA, Formação Docente. 


\section{1- INTRODUÇÃO}

As tecnologias digitais de informação e comunicação (TDIC) transformaram o modo de ser do homem. Desde o seu surgimento, esses recursos modificaram a forma como as relações de trabalho e sociais se desenvolvem. Estão presentes no mercado financeiro, na prestação de serviços e até mesmo nas ações e eventos mais banais do cotidiano.

O que torna essa influência abrangente é a facilidade com a qual se pode acessar toda essa informação. E isso é o que mais há na sociedade do conhecimento. As mais variadas tarefas rotineiras e até mesmo do trabalho podem ser executadas somente com um celular a mão. Basta ter acesso à internet.

Diante desse cenário inovador, a escola não poderia ficar alheia ou imune a esse domínio. Novas concepções de educação ganharam força perante tecnologias cada vez mais avançadas. Tanto na Educação Básica, com as crianças e jovens, quanto no Ensino Superior, nos cursos de licenciatura, os que mais formam professores, entre eles os de Pedagogia, esses recursos transformaram os processos educativos.

A educação online, antes distante, virou uma realidade necessária, uma vez que é preciso formar professores aptos a lidar com esses recursos tecnológicos. Um processo que terá êxito somente se for proporcionada uma imersão significativa nessas linguagens e ferramentas digitais. Diante desse cenário, coloca-se a seguinte questão: Qual o papel dos ambientes virtuais de aprendizagem (AVA) no Ensino Superior na atualidade?

Entende-se, a princípio, que os ambientes virtuais de aprendizagem são elos importantes para o êxito da educação online, sobretudo no Ensino Superior. Eles simbolizam a evolução das TDIC no ciberespaço, possibilitando novas metodologias de ensino-aprendizagem e formas de conduzir o processo educativo.

Portanto, este estudo tem o objetivo de investigar a importância dos AVAs nos cursos de formação do Ensino Superior. Além disso, pretende também estabelecer qual a relação dos AVAs com as TDIC.

Assim, este trabalho foi organizado por meio de pesquisa bibliográfica das principais fontes sobre o tema. Na primeira parte, explora a presença das TDIC no cotidiano, na educação e sua influência na formação de professores. A seguir, apresenta a educação online como um recurso oriundo da evolução das TDIC. Por fim, retrata os AVAs como elementos fundamentais da estrutura de qualquer curso online, sem os quais qualquer proposta educativa dificilmente terá êxito. 


\section{2- REFERENCIAL TEÓRICO}

\section{2-1 AS TDIC NA EDUCAÇÃO E NA FORMAÇÃO DE PROFESSORES}

Atualmente, o mundo vive um momento incomum e crítico e, em meio a tantas incertezas, a tecnologia se apresenta como um caminho na solução de inúmeros problemas, além de encurtar a distância entre as pessoas. A sociedade está cada vez mais imersa nas tecnologias digitais de informação e comunicação (TDIC) nos seus mais diversos segmentos. A história nos mostra que o novo, o imprevisível e os avanços tecnológicos podem transformar as relações sociais e contribuir para a evolução da humanidade.

Existem inúmeras discussões sobre tecnologias nos mais variados contextos contemporâneos. Segundo Portela Cysne (2005, p. 56):

Etimologicamente, techne vem tanto do grego, significando arte, técnica ou habilidade, quanto do teks do Indo-Europeu e significa tecer ou fabricar. Assim, tecnologia pode ser considerada um elemento cultural, ao se considerar que é a capacidade humana de criar tecnologia que torna homem diferente de outros animais. Só o homem tem a habilidade para ampliar seu ambiente natural através do desenvolvimento e uso da tecnologia.

Foi a partir das décadas de 60 e 70, que o mundo passou a experimentar uma nova forma de interação, no qual, graças às tecnologias, sociedade, economia e cultura estavam interligadas. Dessa forma, os recursos tecnológicos, lançados no mercado a cada dia, vêm ditando novas formas de vivências sociais, sendo inegável o poder transformador das tecnologias para a sociedade (CASTELLS, 2010).

Contudo, na educação brasileira de um modo geral, percebe-se que a integração das TDIC ainda acontece de maneira modesta, como descrevem Almeida e Valente (2012, p.58):

Ainda não observamos nos processos de ensino e de aprendizagem, em distintos níveis, do Básico ao Superior, os mesmos impactos e transformações visivelmente identificados em outros segmentos, tais como sistema bancário, nos processos administrativos, nos serviços e nas empresas em geral.

Devido à importância e ao destaque que ocupam no cenário mundial, as TDIC e seus recursos devem ser incorporados aos processos educativos como uma ferramenta pedagógica que muito pode contribuir para qualificá-los, uma vez que as necessidades de aprendizagem mudaram. Assim, faz-se necessário perceber que essas novas formas de comunicação sinalizam para novos caminhos de ensino.

Esses novos contextos sociais levam à necessidade de uma melhor compreensão sobre as tecnologias e os impactos causados a partir da integração das TDIC nos cursos de formação de professores. As exigências da contemporaneidade modificaram também a demanda dos cursos de formação, de modo que as tecnologias passassem a ser incorporadas a esses cursos, uma vez que a educação presencial vem mostrando-se frágil por diversos aspectos.

Nesse sentido, a educação online surge como alternativa para complementar o aprendizado e atender às novas demandas. De acordo com Almeida e Valente (2012, p.60), “[...] as TDIC 
propiciam a reconfiguração da prática pedagógica, a abertura e plasticidade do currículo e o exercício da coautoria de professores e alunos".

Embora muitos autores considerem que os processos pedagógicos devam auxiliar o aprendiz a construir conhecimento, a integração das TDIC nos cursos de formação ainda está muito distante das necessidades contemporâneas. Estudos demonstram que muitos cursos já integraram a seus currículos muitas disciplinas tecnológicas, contudo essas medidas não asseguram a qualidade necessária, nem a utilização de todas as potencialidades oferecidas pelas novas tecnologias digitais.

Segundo Dantas (2005, p.22):

A introdução de uma disciplina tem seu valor enquanto garantia de que o tema será tratado na formação inicial, mas uma proposta de formação adequada à realidade, deve fazer com que a preparação do professor para o uso das TCI perpasse toda a formação, devendo se desenvolver pautada na interdisciplinaridade, na relação teoria-prática, na interação universidadeescola e conteúdo específico - conteúdo pedagógico, etc.

Gatti (2013) reforça a ideia de que existe uma crise nos modelos de formação de professores demandada por questões sociais diversas que levam a inúmeros desafios contemporâneos a serem enfrentados para se atingir uma formação de melhor qualidade, na qual o professor esteja preparado para exercer uma prática contextualizada que leve os alunos a um aprendizado significativo e atenda às suas expectativas escolares.

A preocupação com a educação escolar, com a escola, nos reporta a pensar em pessoas, em relações pedagógicas intencionais, portanto, em profissionais bem formados para isso, dentro das novas configurações sociais e suas demandas; profissionais detentores de ideias e práticas educativas fecundas, ou seja, preparados para a ação docente com consciência, conhecimentos $e$ instrumentos (GATTI, 2013, p.54).

O surgimento e a tomada do cotidiano pelas TDIC influenciam as relações sociais e causa um efeito cascata na educação: escola, professores e universidades precisam se adequar à essas novas linguagens que proporcionam diferentes formas de interação. Novos modelos de educação passam a ganhar força e destaque. Um deles, já citado, é o modelo online.

\section{2-2 OS REFLEXOS DA EDUCACÃO ONLINE NOS PROCESSOS EDUCATIVOS}

Há muitos modelos educacionais que têm as TDIC como base. Neste estudo, o foco é no modelo de educação online. Para Santaella (2013), a educação online é uma modalidade de educação que se processa por meios tecnológicos com a utilização da internet e seus recursos, visando transpor delimitações de espaço e de tempo. É uma forma de ensino e aprendizagem que se processa por meios eletrônicos, em ambientes virtuais de aprendizagem (AVA) e que vem complementar o modelo de educação formal presencial.

Nesse cenário conectado, uma educação híbrida, na qual os processos de ensino e aprendizagem presenciais se mesclam ao online promovendo a combinação entre experiências pedagógicas e 
tecnologias digitais informação e comunicação e informação a educação online tornou-se indispensável no processo educativo.

Segundo Brito e Fofonca (2018, p.12-13):

[...] para uma educação híbrida ocorrer deve haver a compreensão de que o ato de ensino e aprendizagem, mesmo na educação presencial, pode e deve desfrutar de espaços ao sabor da ubiquidade, da modalidade tecnológica e da hipermobilidade e, transformando o fazer uso de ambiências virtuais de aprendizagem um lugar comum, seja para complementar a didatização presencial, seja pela busca da solidez na constituição de aprendentes pesquisadores e curadores de conhecimento em mídias digitais, fato que perpassa a didatização tradicional e ecoa numa ecologia, em que indivíduos, sistemas, objetos de aprendizagem entram em conversação/diálogos sem os constrangimentos de um espaço-tempo (pré)determinados pela educação tradicional.

A educação online introduziu mudanças significativas nos processos educativos, possibilitando aos seus usuários uma aprendizagem ubíqua, com acesso a um fluxo muito grande de informações, com mais flexibilidade e momentos de interação. Há ainda muitos obstáculos a serem enfrentados, mas sabe-se, hoje, que é possível atingir experiências de aprendizagem significativas utilizando a educação online, pois esta dispõe de inúmeras ferramentas e recursos disponíveis para aplicações pedagógicas.

Brito e Fofonca (2018) consideram que a tecnologia possibilita a integração entre os espaços e tempos, onde o mundo digital nada mais é do de uma extensão do mundo físico. Portanto, não são dois espaços diferentes. A esfera digital permite o conceito de sala de aula ampliada, fortalecendo sua concepção híbrida ao facilitar os processos educativos não somente no espaço físico da sala de aula, mas nos múltiplos espaços do cotidiano.

Nesse contexto, a função do professor fica cada vez mais relevante para uma transformação social tão necessária.

Os professores são os mobilizadores da educação escolar e a escola é hoje a instituição social basilar na instrução e formação da vida civil, porta para outras formações e para a construção continuada da democracia e a luta pelos direitos humanos. Sua atuação coloca-se, assim, entre a exclusão social e a transformação (GATTI, 2013, p.59-60).

A educação online pode ser considerada já uma realidade consolidada. É evidente que em constante reconstrução. Mas, por exemplo, em situações de extrema emergência, como se constata perante a COVID-19, vem provando ser uma alternativa consistente e valorosa. Muitas universidades, para não paralisarem totalmente seus serviços, estão fazendo uso mais abrangente dessa modalidade.

Contudo, existe um aspecto que é fundamental dentro desse quadro que contempla a educação online. Para ela ter êxito na sua proposta, necessita, intrinsecamente, dos ambientes virtuais de aprendizagem (AVAs). Sem estes últimos, o objetivo de proporcionar uma extensão da sala de aula em qualquer lugar fica prejudicada. Assim, quando se fala em educação online, não se pode ignorar a importância dos AVAs. 


\section{2-3 OS AMBIENTES VIRTUAIS DE APRENDIZAGEM NA EDUCAÇÃO ONLINE}

A educação online (também chamada $\mathrm{EaD}$ ) é o modelo que possibilita o controle do tempo e espaço em prol da educação. $\mathrm{O}$ aluno estuda quando e onde quiser. Ele pode se organizar e escolher o melhor momento para que o estudo seja efetivo, mesmo que esteja bem longe da sala de aula. Basta ter acesso à internet.

A internet, dessa maneira, não se limita a um meio de transmissão de informações, ela abre um novo mundo de organização social. A educação via internet, por sua vez, passa a comportar elementos que encontram confluência com o que deve ser a formação de um novo tipo de sujeito social: o sujeito em rede (BARROS, 2015, p.202).

A utilização da internet promove uma interação maior entre alunos e professores, além de alunos com outros colegas de turma, em um espaço de produção coletiva e troca de informações e conhecimentos que podem ir além dos horários de aula. Mas essa interação, essa nova metodologia de ensino-aprendizagem só é possível por meio do ambiente virtual de aprendizagem (AVA). Basicamente, é o alicerce sobre o qual a educação online (ou EaD) é construída.

Para começar, é importante compreendermos o ambiente virtual de aprendizagem como o sistema que gerencia os cursos online. É nele que os participantes do curso realizam suas tarefas, buscam seus materiais de leitura, interagem com os demais participantes, são acompanhadas pela equipe docente etc (RIBEIRO, 2020, p.25).

Dessa forma, a ênfase dos AVAs é promover os processos de aprendizagem. Os participantes do curso possuem flexibilidade para estruturar suas atividades, mas o que não impede, por exemplo, de serem monitorados por meio dos registros do ambiente afim de que se possa acompanhar os seus respectivos progressos.

Pereira (2007) afirma que os AVAs se baseiam em mídias que usam o ciberespaço para disseminar conteúdos e propiciar as interações entre os integrantes do processo educativo. A qualidade desse último, portanto, é o resultado da soma de vários fatores: envolvimento do aluno; qualidade da proposta pedagógica; dos recursos disponibilizados além da estrutura e qualidade da equipe docente.

Os AVAs são tecnologias digitais que foram criadas para e-learning (aprendizagem eletrônica) e que oferecem conteúdos a distância, disponibilizando ferramentas on-line (síncronas e assíncronas) para serem utilizadas por pessoas que porventura naveguem nos ambientes (SANTINELLO, 2015, p.37-38).

$\mathrm{O}$ e-learning é um espaço que pode ser considerado um AVA porque permite comunicação e interatividade tanto online como offline. Os AVAs, assim, usam, de forma integrada, sistemas comunicativos e interativos voltados para a educação, dando suporte às estratégias pedagógicas idealizadas pela equipe de professores. Ribeiro (2020) cita como exemplos de ambientes virtuais que transformam o ensino-aprendizagem online o Moodle, WebCT, Blackboard Learning, TelEduc além do Fronter. Porém, existem outros tantos. 
É importante tratar dessas ferramentas digitais dos sistemas de educação online porque esta é uma modalidade que simboliza a expansão da educação e os AVAs é que vão possibilitar seu crescimento. Com a expansão da internet e o seu consequente estabelecimento na área da educação, esse parece um processo irreversível dentro de uma concepção voltada para a sociedade do conhecimento.

\section{2-4 OS DADOS ATUAIS DA EDUCAÇÃO A DISTÂNCIA NO BRASIL}

Tão importante quanto falar dos recursos disponíveis para a educação EAD é falar dos dados que envolvem essa modalidade de ensino. Os países desenvolvidos adotam métodos de educação a distância a muitos anos, no Brasil a educação por correspondência podia ser encontrada nas agencias dos correios e até mesmo nas bancas de revistas. Tal sistema, que antes era conhecido como sistema de educação por correspondência evoluiu e hoje se tornou mais acessível, mesmo para os lugares mais remotos do mundo. Um cidadão na Antártida pode fazer um excelente curso em plataformas da Harvard, por exemplo.

Tudo isso chamou a atenção do sistema de educação formal e em o Governo Federal lançou o chamado projeto EDUCOM. Porém antes mesmo do lançamento do referido projeto, a informatização já estava em andamento, ainda nos anos 60 o departamento de física da Universidade Federal do Rio de Janeiro (Moraes, 1997, pág. 20) já passava por experiencias com computadores na educação.

O Projeto EDUCOM foi o primeiro projeto de natureza publica voltado para a educação, criado em 1983 e capitaneado por uma comissão da SEI deu início a implantação de sistemas de informática educacionais em várias universidades públicas. Até esse momento não tinha noção da dimensão e do avanço das metodologias de ensino por parte dos sistemas de ensino a distância.

Com o tempo aos Ambientes virtuais foram se modernizando e se democratizando, surgindo dezenas de plataformas de ensino extremamente acessíveis, como: Moodle, Teleduc, E-proinfo, Dokeos, Sakai, Blackboard, WebAula, Saba, Sumtotal e etc.

A ABED, Associação Brasileira de Ensino a distância registrou no ano de 2017 um recorde em número de matriculados são de aproximadamente 1.8 milhão, com crescimento de $17,6 \%$ de 2016 para 2017 e cerca de $21,2 \%$ do total de alunos matriculados no ensino superior do país.

É fato que as plataformas precisam se modernizar e com isso suprir as necessidades de um estudo de qualidade, o que vem ocorrendo a passos largos na educação a distância.

\section{3- METODOLOGIA}

O presente estudo utiliza pesquisa bibliográfica exploratória como ponto de partida para tratar o tema da Educação Online e Ambientes Virtuais de Aprendizagem no Ensino Superior além das suas consequências nas metodologias de ensino-aprendizagem nos cursos de formação de professores. 
O foco da proposta foi verificar a importância dos ambientes virtuais de aprendizagem nos cursos de formação do Ensino Superior além relacioná-los com as tecnologias digitais da informação e comunicação.

\section{CONSIDERAÇÕES FINAIS}

De tudo o que foi exposto até aqui, depreende-se que a integração das TDIC no espaço escolar, em especial nos cursos de formação docente, oferece uma oportunidade para impulsionar a educação. Isso significa alçar outros patamares, elevar o nível de interação e as formas de construção do conhecimento durante o processo educativo.

Sabe-se que a constante renovação das TDIC e o processo de evolução dos AVA acabam tornando-se desafios a serem enfrentados pelos docentes em sua ação. Contudo, a utilização das tecnologias digitais em contextos pedagógicos aponta para uma aprendizagem significativa, num espaço propício para interação entre os participantes e para a construção de conhecimento.

Evidencia-se, portanto, que os AVA possibilitam uma aprendizagem na qual os alunos sentemse engajados em uma prática mais dinâmica que os permite interagir com professores e outros colegas num processo de educação online. Além disso, esses ambientes virtuais reúnem diversas linguagens próprias da era das TDIC, sem os quais qualquer proposta de educação online que almeje êxito fica prejudicada.

Nessa perspectiva, trabalhar com a realidade posta e favorecida pelos AVA torna-se também um desafio para os cursos de formação inicial e continuada de professores, uma vez que precisam apresentar mudanças didáticas que preparem o docente para a realidade contemporânea. Esta exige, cada vez mais, uma combinação de experiências presenciais e virtuais de aprendizagem.

Nosso propósito neste estudo é contribuir com uma possível reflexão para professores que procuram integrar as TDIC em sua ação docente, na qual a aprendizagem e a construção do conhecimento são o foco principal e as tecnologias sejam entendidas como instrumentos de mediação para atingir esse objetivo. 


\section{BIBLIOGRAFIA}

ALMEIDA, M. E. B.; VALENTE, J. A. Integração currículo e tecnologias e a produção de narrativas digitais. Currículo Sem fronteira, 12 (3), p.57-82.

BARROS, JOY N. DA S. Educação a distância: democracia e utopia na sociedade do conhecimento [livro eletrônico]. Camipnas, SP: Papirus, 2015.

BRITO, G. S.; FOFONCA, E. Metodologias Pedagógicas Inovadoras e Educação Híbrida: para pensar a construção ativa de perfis de curadores de conhecimento. In: FOFONCA, E. et al. Metodologias Pedagógicas Inovadoras: contextos da Educação Básica e da Educação Superior. Curitiba: Editora IFPR, 2018, v. 1, p.12-24.

CASTELLS, M. A sociedade em rede: a era da informação: economia, sociedade e cultura. São Paulo: Paz e Terra, 2010.

DANTAS, Aleksandre Saraiva. A formação inicial do professor para o uso das tecnologias de comunicação e informação. HOLOS, [S.I.], v. 1, p. 13-26, dez, 2007.

GATTI, Bernardete A. Educação, escola e formação de professores: políticas e impasses. Educar em Revista, [S.I.], v. 29, n. 50, pp. 51-67, dez. 2013.

PEREIRA, A. T. C. (org.). AVA - Ambientes virtuais de aprendizagem em diferentes contextos. Rio de Janeiro: Ciência Moderna, 2007.

PORTELA CYSNE, Fátima. Transferência de tecnologia entre a universidade e a indústria. Encontros Bibli: revista eletrônica de biblioteconomia e ciência da informação, núm. 20, segundo semestre, 2005, pp. 54-74 Universidade Federal de Santa Catarina Florianópolis, Brasil.

RIBEIRO, Renata Aquino. Introdução à EaD. 2.ed. São Paulo: Pearson Education do Brasil, 2020 .

SANTAELLA, Lucia. Comunicação ubíqua: Repercussões na cultura e na educação. São Paulo: Editora Paulus, 2013, p. 294-307.

SANTINELLO, Jamile. Ensino superior em ambientes virtuais de aprendizagem (AVAs): formação docente universitária em construção [livro eletrônico]. Curitiba: Intersaberes, 2015 .

TAVARES, Neide Rodrigues Barea. História da informática educacional no Brasil observada a partir de três projetos públicos. Disponível em: http://www.apadev.org.br/pages/workshop/historiaInf.pdf. Acesso em 17.04.2020

LIMA, Cláudia de castro. Educação a distância: um modelo que só cresce. Disponível em: https://forbes.com.br/negocios/2019/03/educacao-a-distancia-um-modelo-que-so-cresce/.

Acesso em 17.04.2020 